ORIGINAL ARTICLE

\title{
A study of public opinion on the use of tissue samples from living subjects for clinical research
}

\author{
M L Goodson, B G Vernon
}

J Clin Pathol 2004;57:135-138. doi: 10.1136/icp.2003.9886

\begin{abstract}
See end of article for authors' affiliations

......................

Correspondence to: Ms M L Goodson, Schoo of Population and Health Science, University of Newcastle, Newcastle upon Tyne NE2 $4 \mathrm{HH}$, UK; M.L.Goodson@ncl.ac.uk

Accepted for publication 5 June 2003
\end{abstract}

\begin{abstract}
Aims: To assess public opinion on the use of tissue samples from living adults and children for clinical research.

Methods: A questionnaire study of 100 healthy volunteers (100\% response rate) from a Newcastle NHS dental practice. The issues investigated were the types of tissues that individuals were prepared to donate for research, the type of research donors would be prepared to consent to, and attitudes to research on children's tissues.

Results: Eighteen per cent of the participants said that they would not give consent for research to be carried out on their tissues, $50 \%$ would not give consent for the donation of a child's tissues. Only $26 \%$ of subjects said that they would give consent for research on genetic cloning compared with $82 \%$ for cancer research. Sex differences existed in the responses.

Conclusions: Greater research attention needs to be given to public opinion on the use of tissue from living subjects for medical research to facilitate drafting of new legislation.
\end{abstract}

$\mathrm{T}$ he Alder Hey and Bristol Royal Infirmary inquiries ${ }^{2}$ attracted considerable negative publicity surrounding the use of tissue samples for medical research. These inquiries dealt with postmortem organs and tissues retained from children and highlighted the need for changes to existing legislation governing the removal, retention, and use of tissues and organs both from dead and living subjects. To safeguard and reassure the public against malpractice, several guidelines are being considered, which aim to facilitate research within a secure legal framework, without fear of inadvertent harm to tissue donors and loss of public confidence.

The debate surrounding property rights and the need for consent is ongoing. ${ }^{3}$ The Nuffield Council on Bioethics ${ }^{4}$ examined issues surrounding ownership of human tissue and proposed that tissue removed from patients in the course of treatment should be considered abandoned, denying tissue donors rights over their removed tissue. These proposals were tested in a study on a group of surgical inpatients, ${ }^{5}$ and the results strongly support the use of surgically removed tissues in medical education, research, and science. In that study, few patients believed that they retained ownership of tissue removed at surgery, and most believed that postoperatively the tissue belonged to the hospital, to nobody, or to the laboratory, although these surgical inpatients may not be a representative sample of the population, having just experienced tissue removal themselves. It is not clear whether patients were unidentifiable in the study, and they may possibly have felt coerced in their questionnaire responses because the study was undertaken by the patients' own team of pathologists/surgeons.

\section{"Current statutory and case law recognises the autonomy of patients' decisions over their bodies, but not ownership of tissue or the extent of autonomy"}

Interestingly, and more recently, the Royal College of Pathologists stated that $99 \%$ of 2000 subjects in Peterborough supported tissue donation from living subjects for research. ${ }^{6}$
Current statutory and case law recognises the autonomy of patients' decisions over their bodies, but not ownership of tissue or the extent of autonomy. ${ }^{7}$ It would seem plausible that if individuals are able to opt out of tissue donation or expect control over use of their tissue postoperatively, there is a danger of losing donations of particular tissue types, particularly tissue from children, which could impact negatively on research and teaching.

Recent Department of Health recommendations ${ }^{8}$ advise that patients should be given the opportunity to refuse permission for tissue taken during surgery to be used for education and research purposes. This would result in what might be called "conditional consent", and the recommendations advise patients that they should record objections to particular uses or the use of particular tissues preoperatively.

Current guidelines and recommendations are clearly numerous, but principally drawn up by clinicians and legislative bodies with limited knowledge of public opinion.

The aims of our study are fourfold:

(1) To assess what tissue types individuals would be prepared to donate for research.

(2) To assess what types of research people would be happy to donate tissues for.

(3) To assess whether adults would be prepared to consent to the donation of a child's tissues.

(4) To assess whether individuals would be happy for their tissues to be used to teach medical students.

\section{METHODS}

One hundred healthy adult volunteers were recruited from a National Health Service dental practice. No volunteers were attending the practice for extractions or mucosal biopsies. Ethical approval for our study was granted by Newcastle and North Tyneside joint ethics committee. A patient information leaflet was given to each volunteer and informed consent was obtained. Volunteers were invited to complete an anonymous questionnaire (fig 1) then place the questionnaire in a box. If any of the volunteers did not understand the questionnaire, they were invited to ask questions of the researcher (MG). 
Q1. Would you be happy for pieces of any of the following body tissues or organs to be used in clinical research? (circle any that are appropriate)

$\begin{array}{lll}\text { Eyes } & \text { Lung } & \text { Heart } \\ \text { Tissue of head and neck } & \text { Embryo } & \text { Brain } \\ \text { Ovary/Testes } & \text { Bone } & \text { Breast }\end{array}$

Q2. What kind of research would you be happy for your tissues to be used for? (circle any that are appropriate)

$\begin{array}{lll}\text { Cancer research } & \begin{array}{l}\text { Genetic research for } \\ \text { diagnosis or treatment of, } \\ \text { for example, Down's syndrome }\end{array} & \begin{array}{l}\text { General knowledge } \\ \text { of body tissues }\end{array} \\ \text { Testing medicines } & \text { Genetic cloning } & \end{array}$

Q3. Would you want to be informed if your tissues were to be stored beyond the time required for diagnosis?

Q4. Would you want to be consulted if research was to be undertaken on stored tissue in the future?

Q5. Would you be happy to give consent for a child's tissues to be used for scientific research?

Q6. Would you be happy to give consent for your tissues to be used to teach medical students?

Statistical comparisons of male/female responses were carried out using standard errors of percentage.

\section{RESULTS}

In total, 100 questionnaires were completed (100\% response rate) and all figures quoted are percentages of the total number of responders $(n=100)$. Sixty five per cent of respondents were women and 35\% were men. Eighteen per cent of subjects were aged 20-30 years, 20\% aged 30-39 years, $25 \%$ aged $40-49$ years, $24 \%$ aged $50-59$ years, and $13 \%$ aged 60-69 years.

Eighteen per cent of subjects would not agree to donation of any of the listed body tissues and the least popular tissue donations were tissues of the eye (54\%), brain (58\%), lung $(58 \%)$, and bone $(50 \%)$. The most popular tissue donations were tissues of the head and neck (74\%) and ovarian/

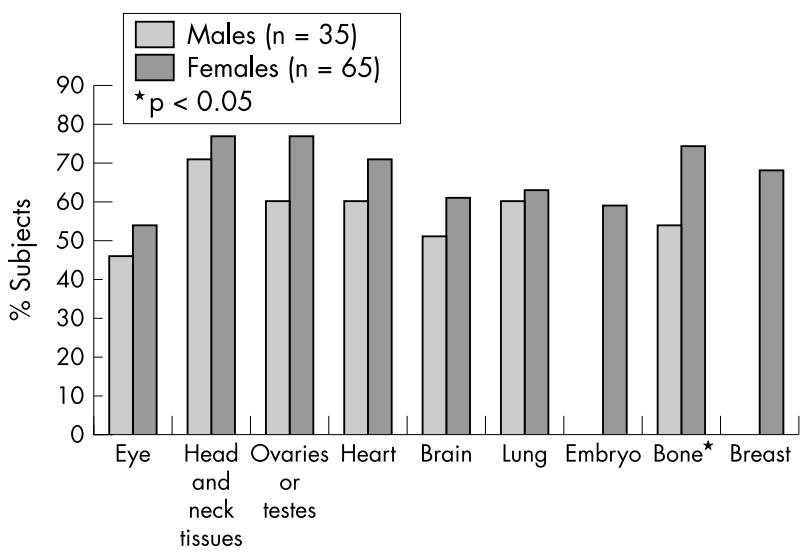

Figure 2 Which of the following body tissues would you be prepared to donate for clinical research?
Figure 1 The structure of the questionnaire.
Figure 3 What kinds of research would you be happy for pieces of your body tissues or organs to be used for?

testicular tissue $(71 \%)$; however, sex differences existed for responses to question 1 (fig 2).

Responses to question 2 revealed that $82 \%$ would be happy for their tissues to be used for cancer research. Only $65 \%$ of respondents would give consent for their tissues to be used for research into genetic disorders; 59\% would give consent for research on general knowledge of body tissues and 59\% would give consent for testing medicines. Only $26 \%$ of responders indicated that they would be happy for their tissues to be used in research on genetic cloning. Again, sex differences existed in responses to question 2 (fig 3).

Responses to the remaining questions (fig 4) indicated that $42 \%$ of subjects would want to be informed if their tissues were going to be stored after donation and 35\% stated that they would want to be consulted if their tissues were to be used for further research.

Fifty per cent of subjects said that they would be happy to give consent for a child's tissues to be used in research and $72 \%$ of responders said that they would agree to their tissues being used to teach medical students. Again, sex differences existed in responses.

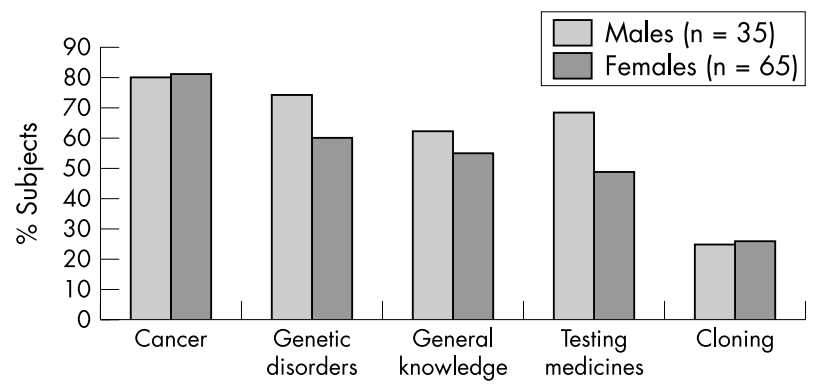




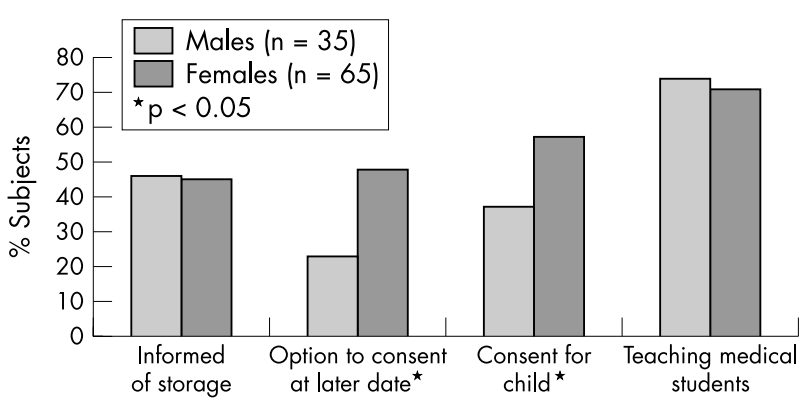

Figure 4 Public opinion on consent for further research, children, and teaching medical students.

\section{DISCUSSION}

Subjects in our study were recruited from a National Health Service dental practice rather than primary or secondary care to remove bias attached to studies of surgical patients or patients attending primary care physicians for conditions relating to tissue removal.

Questionnaires were completed at the practice waiting area between $9.00 \mathrm{am}$ and $7.00 \mathrm{pm}$. The percentage sample of female responders was higher than that of male responders. The $100 \%$ response rate reflected the interest of participants in tissue donation, the brevity of the questionnaire, and the lack of other activities in the dental practice waiting room.

A pilot study was carried out initially to ensure that the questionnaire was easy to complete and lacked ambiguity. For question 1 , the body tissues listed were chosen for variety of emotional connotations.

Our study clearly showed that, in contrast to previous studies, ${ }^{56}$ a large minority of responders were not prepared to donate any of the listed tissues for research. The reasons for this are unknown, but could be the result of recent negative publicity surrounding postmortem organ retention and reports of medical malpractice/criminal behaviour. When previous studies ${ }^{56}$ were published, considerably less media attention had been given to tissue/organ retention, and public faith in researchers and the medical profession as a whole may have been greater. In addition, our study was carried out on healthy subjects, and tissue samples for research are most commonly acquired when surgery is undertaken to remove pathological tissue. If, as in previous studies, only $1-2 \%$ of subjects object to tissue donation in the hospital setting, have these patients gained new knowledge and altered opinions by virtue of their experiences in hospital, or have they developed greater interest in assisting medical research for perceived personal gain?

\section{"Our study clearly showed that, in contrast to previous studies, a large minority of responders were not prepared to donate any of the listed tissues for research"}

The next issue that we wish to focus on here is "who should be obtaining informed consent for research projects?". Consent is commonly obtained by doctors, whose primary focus is to carry out surgery for a patient. In many cases, however, these doctors are also involved in the research project for which consent is being sought. As a result of this, might patients feel coerced into tissue donation to please their surgeon?

The findings of our study showed that eye, bone, and brain tissues were the least popular tissue donations. The reasons for this are unclear, but these tissues may be viewed emotively. Tissues of the head and neck and ovarian/ testicular tissues were found to be the most acceptable donations, and this may be because egg and sperm donation is familiar and widely accepted in fertility treatment. Tissue of the head and neck is a generic category encompassing several tissues and, retrospectively, may not have been a useful category to use when trying to identify specific tissues that individuals may not want to donate.

Responses for embryo and breast were obtained only from women: over $50 \%$ said that they would consent to donation of these tissues, even though donation of such tissues could be seen as emotionally charged and therefore unacceptable. Consent for heart and lung donations did not differ greatly between men and women.

The types of research listed in question 2 were selected as currently "hot" media topics and more traditional classes of research.

Cancer research is traditionally well accepted and funded. The $82 \%$ positive response rate here may result from individuals having had friends or relatives affected by cancer, or even personal experience of cancer themselves, which would contribute to their generally positive views on cancer research.

Responses for research on genetic conditions, general knowledge of body tissues, and testing medicines were fairly similar, with a higher percentage of men than women responding positively, but this may purely be a reflection of the small sample size of male subjects.

Positive responses for research on genetic cloning were considerably lower than for other types of research. The reasons for this may be a lack of knowledge on cloning by respondents or negative publicity surrounding cloning in recent months. All those who responded positively to the "genetic cloning" stem of this question responded positively to at least two other stems, so the study appeared to include a group of individuals who were not opposed to research in principle.

Question 3 asked whether subjects would want to be informed if their tissues were to be stored in excess of the time required for diagnosis. This, together with question 4, which relates to whether individuals would want to give consent for research to be carried out on stored tissues, demonstrates that a relatively large number of individuals would want some ongoing control over their tissue after donation, which has implications for the use of existing stored tissues. Several subjects in our study said that they would want to be informed if their tissues were going to be used in the future, although it may be impractical to suggest that researchers should seek consent several years after initial tissue donation. The use of surplus tissue was the subject of a detailed ethical review in $1995 .{ }^{4}$ This review concluded that, in the absence of evidence to the contrary, it was reasonable to assume that a patient's consent to the removal of the tissue implied consent to its subsequent use for any ethically

\section{Take home messages}

- A considerable proportion (18\%) of respondents to a questionnaire on the use of tissue samples from living subjects for clinical research said that they would not give consent for research to be carried out on their tissues

- In addition, $50 \%$ would not give consent for the donation of a child's tissues, and only $26 \%$ said that they would give consent for research on genetic cloning, compared with $82 \%$ for cancer research

- Greater research attention needs to be given to public opinion on the use of tissue from living subjects for medical research to facilitate drafting of new legislation 
acceptable purpose. However, according to our study, such assumed consent does not command universal public support.

Responses to question 5 suggest that obtaining tissue from children may be difficult. This may again be the result of negative publicity from the Alder Hey Inquiry, but it should be remembered that in our study, no distinction was made between individuals with and without current responsibility for consent for a child, and in future studies it might be useful to exclude the "childless" group.

Question 6 refers to whether subjects would be happy to donate tissue samples to assist with the teaching of medical students. Most subjects responded positively to this question and there were no significant sex differences.

"Public education in understanding the principles and benefits of clinical research is an essential process towards the re-establishment of public confidence in medical research practice"

At present, guidelines for obtaining tissue samples from living subjects are still under scrutiny and before new legislation can be developed several of the cited issues need to be addressed, both through further research and debate between all parties involved including clinicians, researchers, and the general public. Most importantly, however, public education in understanding the principles and benefits of clinical research is an essential process towards the re- establishment of public confidence in medical research practice.

\section{ACKNOWLEDGEMENTS}

We would like to acknowledge Newcastle Medical School for allowing this project to be undertaken as a student selected module and the Institute of Medical Ethics for a medical student research bursary.

\section{Authors' affiliations}

M L Goodson, B G Vernon, School of Population and Health Sciences, The Medical School, University of Newcastle, Newcastle upon Tyne NE2 $4 \mathrm{HH}, \mathrm{UK}$

\section{REFERENCES}

1 Burton JL, Wells M. The Alder Hey affair: implications for pathology practice. $J$ Clin Pathol 2001;54:820-3.

2 Evans HM. What's wrong with "retained organs"? Some personal reflections in the afterglow of "Alder Hey". J Clin Pathol 2002;54:824-6.

3 van Diest PJ, Savulescu J. For and against: no consent should be needed for using leftover body material for scientific purposes. BMJ 2002;325:648-51.

4 Nuffield Council on Bioethics. Human tissue: ethical and legal issues. London: Nuffield Council on Bioethics, 1995.

5 Start RD, Brown W, Bryant RJ, et al. Ownership and uses of human tissue: does the Nuffield Bioethics report accord with the opinion of surgical inpatients. BMJ 1996;313:1366-8.

6 The Royal College of Pathologists. Human bodies, human choices: response from the Royal College of Pathologists (http://www.rcpath.org), 2002.

7 The Royal College of Pathologists. Consensus statement of recommended policies for uses of human tissue in research, education and quality control. London: Royal College of Pathologists, 1999.

8 Department of Health. Model policy for consent to examination or treatment (http://www.doh.gov.uk/consent), 2002. 